\title{
Comparison of Dissolution Profiles of Formulations Containing Ferrous Sulfate and Fumarate
}

\author{
S. Basualdo ${ }^{1}$, H. Torti ${ }^{2}$, J. Fuda ${ }^{2}$, \\ M. Nuñez ${ }^{3}$, and A. I. Segall ${ }^{1, *}$ \\ ${ }^{1}$ Cátedra de Control de Calidad de Medicamentos, Facultad de Farmacia y Bioquímica, \\ Universidad de Buenos Aires, Buenos Aires, Argentina \\ ${ }^{2}$ Cátedra de Física, Facultad de Farmacia y Bioquímica, Universidad de Buenos Aires, Buenos Aires, Argentina \\ ${ }^{3}$ Cátedra de Matemática, Facultad de Farmacia y Bioquímica, Universidad de Buenos Aires, Buenos Aires, Argentina
}

\section{ABSTRACT}

The aim of the present study was to evaluate and compare the dissolution profiles of seven commercial products containing ferrous sulfate and fumarate marketed in Argentina, based on their in vitro dissolution characteristics using USP Apparatus 2.

\section{INTRODUCTION}

ron deficiency is one of the most common nutritional deficiencies throughout the world, and the most severe form manifests as anemia. Both iron deficiency and anemia have severe repercussions on immune function, physical capacity for work, and attention span (1-3). In females, there is a risk of iron deficiency due to regular menstrual blood loss and the increase of iron demand during pregnancy. Peptic ulcer disease and nonsteroidal, anti-inflammatory drugs are common causes of blood (and therefore iron) loss. Anemia may be secondary to inflammatory or infectious diseases (4-7) or to a diet lacking other micronutrients essential for iron metabolism such as vitamins $C, A, B_{12}$, and folate (8). Given the frequency of iron deficiency and diseases resulting in iron loss, it is not surprising that iron preparations are among the most commonly prescribed drugs in Argentina and that iron salts are components of many vitamin and mineral supplements (9). In fact, about $10 \%$ of elderly persons ingest over-the-counter preparations containing iron, and the standard medical care for pregnant woman includes iron supplementation.

Iron absorption takes place at the duodenum and the upper jejunum of the gastrointestinal system. Even if there is no absorption in the stomach, this organ contributes to the process by the secretion of hydrochloric acid and enzymes, which help not only to set iron free from the food matrix but also to make it soluble (10-12).

Iron absorption may be affected by a combination of different factors, such as the type of ingested iron, the nutritional status of the individual for this element, and the presence of absorption activators or inhibitors existing in the intestinal lumen together with iron (13-18). Iron is found in foods in two different groups, hemic iron and non-hemic iron. The heme-type iron is a part of hemo-

${ }^{*}$ Corresponding author. globin, myoglobin, cytochromes, and many other heme proteins, which are present principally in animal foods. The heme group, which is present in all of these proteins, is a complex organic ring, called protoporphyrin, bound to a divalent iron atom that has six coordination sites. Four of the sites are bound to the protoporphyrin, one to a nitrogen atom of the protein fraction, and the remaining site is available to bind to an oxygen molecule.

The non-hemic type iron corresponds to iron that is not bound to a heme group and includes inorganic iron salts that are found principally in vegetal foods as well as in the principal pharmaceutical preparations utilized for iron deficiency therapy (19). Because non-hemic iron is found in a higher proportion in the diet, its absorption is significantly modified by the nutritional status of the individual for this element. Thus, if the natural iron depots are depleted, iron absorption will increase, and if the depots are saturated, iron absorption will decrease. There are different physiological states (e.g., growth and pregnancy) that produce a substantial increase in the absorption of this metal because of an increase in the synthesis of new biomolecules that have iron in their structure (19-23).

The most therapeutically active form of iron is the ferrous form $\left(\mathrm{Fe}^{+2}\right)$. Dietary ferric $\left(\mathrm{Fe}^{+3}\right)$ form is converted to the ferrous form in the stomach. This reduction is greatly promoted by the presence of $\mathrm{H}^{+}$and dietary ascorbic acid. The great advantage of this conversion is that the ferrous form (as compared with the ferric form) is much more easily released from the organic ligands to which it is bound and stays soluble (24) The commercially available salt forms mainly include ascorbate, citrate, fumarate, gluconate, oxide, succinate, and sulfate. The solubilities of these various salts in water or aqueous media are significantly different, and hence it is reasonable to expect that their dissolution rates could vary. Further complications and variations in the release of iron may arise because of changes in the formulation of a product with any given salt form and the presence 
Table 1. Formulation Composition

\begin{tabular}{|c|c|c|c|}
\hline Formula & Active Ingredient & Other Ingredients & Formulation Type \\
\hline I & $200 \mathrm{mg} \mathrm{FeSO}_{4}$ & Not declared & Uncoated tablets \\
\hline II & $525 \mathrm{mg} \mathrm{FeSO}$; folic acid & Not declared & Film-coated tablets \\
\hline III & $\begin{array}{l}330 \text { mg ferrous fumarate; } \\
\text { folic acid; vitamins } B_{12} \text { and } C\end{array}$ & $\begin{array}{l}\text { Sugar; maize starch; povidone; talc; polysorbate 80; silicon dioxide; erythrosin; } \\
\text { Quinoline Yellow; Patent Blue }\end{array}$ & Capsules \\
\hline IV & $\begin{array}{l}525 \mathrm{mg} \mathrm{FeSO} \text {; ascorbic } \\
\text { acid; vitamin B complex }\end{array}$ & $\begin{array}{l}\text { Methyl methacrylate acrylate; povidone; talc; erythrosin; magnesium stearate; } \\
\text { polyethylene glycol 8000; polyethylene glycol; propylene glicol; sorbitan mono- } \\
\text { oleate; castor oil; sodium saccharin; titanium dioxide; celacefato; ethyl vanillin; FD } \\
\text { \& C yellow No. } 6\end{array}$ & Gradumet tablets \\
\hline $\mathbf{v}$ & $\begin{array}{l}525 \mathrm{mg} \mathrm{FeSO} \text {; folic acid; } \\
\text { ascorbic acid }\end{array}$ & $\begin{array}{l}\text { Methyl methacrylate acrylate; povidone; talc; erythrosin; magnesium stearate; } \\
\text { polyethylene glycol 8000; celacefato; maize starch; propylene glicol; sorbitan } \\
\text { monooleate; castor oil; sodium saccharin; titanium dioxide; tartrazine; amaranth }\end{array}$ & Tablets \\
\hline VI & $200 \mathrm{mg} \mathrm{FeSO}_{4}$ & Not declared & Film-coated tablets \\
\hline VII & $200 \mathrm{mg} \mathrm{FeSO}_{4}$ & $\begin{array}{l}\text { Sugar; lactose; maize starch; magnesium stearate; talc; erythrosine red; povidone; } \\
\text { colloidal silicon dioxide; stearic acid; purified shellac; ammonium methacrylate } \\
\text { copolymer type A RL; ammonium methacrylate copolymer type B RS }\end{array}$ & $\begin{array}{l}\text { Tablets with } \\
\text { microgranules }\end{array}$ \\
\hline
\end{tabular}

or absence of any type of coating. There are many iron preparations on the market that can be broadly classified into uncoated tablets, film-coated tablets, modified-release tablets (including enteric-coated and sustained, controlled, and timed types), and certain capsule dosage forms. It has been reported that some of these products are mistakenly used interchangeably. This is perhaps because there is little scientific literature on the dissolution of iron from various products (9). The USP specifies a dissolution test for ferrous sulfate (25) and ferrous fumarate tablets (26). Hence, this study was undertaken for comparative purposes under the specified conditions. The study included commercially available preparations.

\section{MATERIALS AND METHODS}

\section{Reagents}

Analytical grade hydrochloric acid (J.T. Baker, Mexico) and sodium lauryl sulfate (Flamaquímica, Argentina) were used. Ferric nitrate standard substance was purchased from Merck (Darmstadt, Germany). All reagents were of analytical grade.

\section{Materials}

Seven products were purchased commercially and analyzed. Table 1 summarizes the characteristics of the seven products. The products were purchased from pharmacies in Buenos Aires (Argentina). All tests were performed within product expiration dates, which were similar among brands.

\section{Apparatus and Procedure}

All dissolution studies were performed using USP Apparatus 2 (Vankel, VK 7010). The USP ferrous sulfate tablets test (25) was performed at $50 \pm 1 \mathrm{rpm}$. The dissolution medium was $0.1 \mathrm{~N}$ hydrochloric acid at $37 \pm 0.5^{\circ} \mathrm{C}$. The acceptance criterion set was $Q=75$ in $45 \mathrm{~min}$.
The USP ferrous fumarate tablets test (26) was performed at $75 \pm 1 \mathrm{rpm}$. The dissolution medium was $0.1 \mathrm{~N}$ hydrochloric acid containing $0.5 \%$ sodium lauryl sulfate at $37 \pm 0.5^{\circ} \mathrm{C}(Q=75)$.

Dissolution medium volume was $900 \mathrm{~mL}$. In all experiments, 5-mL sample aliquots were withdrawn at 5, 10, 15, 30,45 , and 60 min using micropipettes. An equal volume of fresh medium at the same temperature was replaced to maintain a constant volume during the test. The withdrawn amounts were adjusted in the calculations. All samples were filtered through Whatman Grade 50, 2.7- $\mu$ m filter paper. Adsorption of the ferrous solution to the filter paper was validated previously. Samples were analyzed using atomic absorption spectrometry (Buck Scientific model 200) at $248.3 \mathrm{~nm}$ with an acetylene flame and a slit of $0.2 \mathrm{~mm}$. A calibration curve of ferric nitrate was prepared using solutions containing ferric nitrate between 0 and $3 \mathrm{mg} / \mathrm{L}$.

Twelve tablets or capsules of each preparation were studied to obtain statistically significant results. Capsule

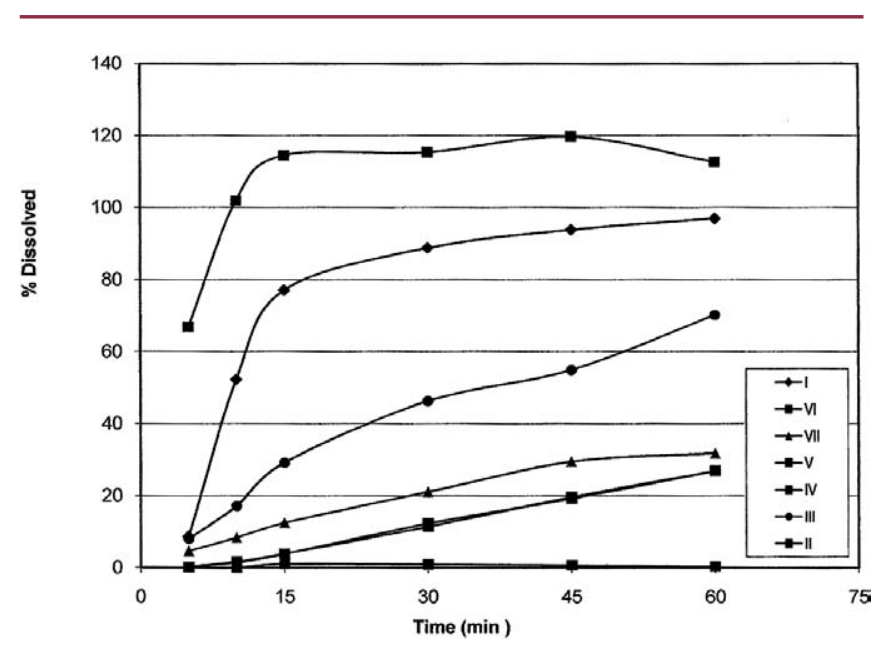

Figure 1.Dissolution profiles. 
Table 2. Dissolution Test Results

\begin{tabular}{|c|c|c|c|c|c|c|c|c|c|c|c|c|}
\hline \multirow{3}{*}{$\frac{\text { Product }}{\text { I }}$} & \multicolumn{12}{|c|}{$\%$ FE Released (Mean and \%RSD) } \\
\hline & \multicolumn{2}{|c|}{$5 \mathrm{~min}$} & \multicolumn{2}{|c|}{$10 \mathrm{~min}$} & \multicolumn{2}{|c|}{$15 \mathrm{~min}$} & \multicolumn{2}{|c|}{$30 \mathrm{~min}$} & \multicolumn{2}{|c|}{$45 \mathrm{~min}$} & \multicolumn{2}{|c|}{$60 \mathrm{~min}$} \\
\hline & 9 & 97.3 & 52 & 23.0 & 77 & 10.0 & 89 & 5.7 & 94 & 5.3 & 97 & 4.0 \\
\hline II & - & & - & & - & & - & & - & & - & \\
\hline III & 8 & 46.1 & 17 & 32.3 & 29 & 30.6 & 46 & 25.8 & 55 & 16.9 & 70 & 14.2 \\
\hline IV & 0.2 & 41.4 & 2 & 17.2 & 4 & 14.6 & 12 & 8.8 & 20 & 6.2 & 27 & 4.3 \\
\hline V & 0.2 & 58.5 & 2 & 29.1 & 4 & 20.5 & 12 & 8.8 & 19 & 10.4 & 27 & 9.6 \\
\hline VI & 67 & 13.9 & 102 & 4.2 & 114 & 3.1 & 115 & 3.2 & 100 & 44.9 & 113 & 2.4 \\
\hline VII & 5 & 14.3 & 8 & 7.3 & 13 & 7.6 & 21 & 5.5 & 30 & 6.2 & 32 & 7.5 \\
\hline
\end{tabular}

sinkers were used to keep the capsules at the bottom of the vessels. To check the supposition of normality of the results, the Shapiro-Wilks test was applied.

If the tablets or capsules did not dissolve due to an enteric coating, the dissolution test was continued after changing the dissolution medium to $\mathrm{pH} 6.8$ phosphate buffer (brands II, III, IV, and VII).

\section{RESULTS AND DISCUSSION}

Dissolution of drug from oral solid dosage forms is a necessary criterion for drug bioavailability (i.e., the drug must be solubilized in the aqueous environment of the gastrointestinal tract to be absorbed). For this reason, dissolution testing of solid oral drug products has emerged as one of the most important performance tests for assuring product uniformity and batch-to-batch equivalence. Variation beyond the pharmacopeial limits indicates unacceptable products $(27,28)$.

The solubility characteristics at room temperature as defined by USP indicate that ferrous sulfate is freely soluble in water, very soluble in boiling water, and insoluble in alcohol; ferrous fumarate is slightly soluble in water and very slightly soluble in alcohol. Its solubility in dilute hydrochloric acid is limited by the separation of fumaric acid (29).

Dissolution profiles and corresponding data are shown in Figure 1 and Table 2, respectively. There was a wide variation in the profiles at $\mathrm{pH}$ 1.2. In this case, only products I and VI met the requirements of USP.

Significant differences between statistical results were obtained ( $p=0.0005)$. Comparisons are shown in Table 3 . It is considered a statistically significant difference when $p<0.05$. There are significant differences between products II and VI, III and VI, IV and VI, V and VI, VII and VI, I and V, and I and IV.

Formulation I was used as reference because it presents the best dissolution profile and is the mark leader. Results of $f_{2}$ calculations are listed in Table 4 . None of the studied profiles is similar to that of formulation I.

No more than $10 \%$ was found dissolved at $\mathrm{pH} 6.8$ for products II, III, IV, and VII. (Data not shown).

\section{CONCLUSION}

This study found widely varying dissolution profiles for iron preparations commonly available in Argentina.
Faster dissolving iron preparations are likely to result in greater bioavailability of iron (9). The slower dissolving iron preparations may be better tolerated, but could lead to treatment failure. It is recommended that faster dissolving iron preparations are used clinically (9). This study is particularly relevant for pregnant women, children, and the elderly, who frequently use iron preparations. Failure to treat iron deficiency adequately can lead to weakness and fatigue due to anemia and can have consequences that are more serious for those with cardiovascular or respiratory disease.

In conclusion, significant differences were seen among the in vitro dissolution profiles of iron from various commercial preparations. Caution is recommended in the interchangeability of marketed iron products.

Table 3. Nonparametric Anova (Kruskal-Wallis)

\begin{tabular}{cllll}
\hline Treatment & \multicolumn{5}{c}{ Ranges } \\
\hline 5 & 11.25 & A & \\
\hline 4 & 11.42 & A & \\
\hline 7 & 16.83 & A & B & \\
\hline 2 & 19.42 & A & B & \\
\hline 3 & 22.67 & A & B & \\
\hline 1 & 30.25 & & B & C \\
\hline 6 & 38.67 & & & $C$ \\
\hline Different letters indicate significant differences $(p \leq 0.05)$ &
\end{tabular}

Table 4. $f_{2}$ Values with Respect to Product I

\begin{tabular}{cc}
\hline Product & $\boldsymbol{f}_{\mathbf{2}}(\mathbf{4 5} \mathbf{~} \mathbf{~ i n})$ \\
\hline II & - \\
\hline III & 21.5 \\
\hline IV & 10.3 \\
\hline V & 10.2 \\
\hline $\mathrm{VI}$ & 20.0 \\
\hline $\mathrm{VII}$ & 13.2 \\
\hline
\end{tabular}

Dissolution Technologies I NOVEMBER 2012 


\section{ACKNOWLEDGMENTS}

This work was supported by grant B072/2008-2010 to A. I. Segall from UBA.

\section{REFERENCES}

1. Iron Deficiency Anaemia: Assessment, Prevention, and Control, A guide for programme managers; $\mathrm{WHO} /$ NHD/01.3; World Health Organization: Geneva, 2001; p 114.

2. Indicators and Strategies for Iron Deficiency and Anemia Programmes; WHO/UNICEF/UNU; World Health Organization: Geneva, 1994; p 123.

3. Duque, X.; Moran, S.; Mera, R.; Medina, M.; Martinez, H.; Mendoza, M. E.; Torres, J.; Correa. P. Effect of Eradication of Helicobacter pylori and Iron Supplementation on the Iron Status of Children with Iron Deficiency. Arch. Med. Res. 2010, 41 (1), 38-45.

4. Gamble, M. V.; Palafox, N. A.; Dancheck, B.; Ricks, M. O.; Briand, K.; Semba, R. D. Relationship of vitamin A deficiency, iron deficiency, and inflammation to anemia among preschool children in the Republic of the Marshall Islands. Eur. J. Clin. Nutr. 2004, 58 (10), 1396-1401.

5. Olivares, M.; Walter, T.; Osorio, M.; Chadud, P.; Schlesinger, L. Anemia of a Mild Viral Infection: The Measles Vaccine as a Model. Pediatrics 1989, 84 (5), 851-855.

6. Oppenheimer, S. J. Iron and Its Relation to Immunity and Infectious Disease. J. Nutr. 2001, 131 (2), 616S-635S.

7. Sarker, S. A.; Davidsson, L.; Mahmud, H.; Walczyk, T.; Hurrell, R. F.; Gyr, N.; Fuchs, G. J. Helicobacter pylori infection, iron absorption, and gastric acid secretion in Bangladeshi children. Am. J. Clin. Nutr. 2004, 80 (1), 149-153.

8. Fishman, S. M.; Christian, P.; West, K. P. The role of vitamins in the prevention and control of anaemia. Public Health Nutr. 2000, 3 (2), 125-150.

9. Bannerman, J.; Campbell, N. R. C.; Hasinoff, B. B.; Venkataram, $\mathrm{S}$. The dissolution of iron from various commercial preparations. Pharm. Acta Helv. 1996, 71 (2), 129-133.

10. Skikne, B. S.; Lynch, S. R.; Cook, J. D. Role of Gastric Acid in Food Iron Absorption. Gastroenterology 1981, 81, 1068-1071.

11. Carpenter, C. E.; Mahoney, A. W. Contributions of Heme and Nonheme Iron to Human Nutrition. Crit. Rev. Food Sci. Nutr. 1992, 31 (4), 333-367.

12. Hernández Garcia, M. Anemia ferropénica. Medicine 1993, 10, 545-554.

13. Bezwoda, W. R.; Torrance, J. D.; Bothwell, T. H.; MacPhail, A. P.; Graham, B.; Mills, W. Iron absorption from red and white wines. Scand. J. Haematol. 1985, 34 (2), 121-127.

14. Charlton, R. W.; Bothwell, T. H. Iron absorption. Annu. Rev. Med. 1983, 34, 55-68.
15. Bothwell, T. H.; Baynes, R. D.; MacFarlane, B. J.; McPhail, A. P. Nutritional iron requirements and food iron absorption. J. Intern. Med. 1989, 226 (5), 357-365.

16. Schümann, K.; Elsenhans, B.; Ehtechami, C.; Forth, W. Rat intestinal iron transfer capacity and the longitudinal distribution of its adaptation to iron deficiency. Digestion 1990, 46 (1), 35-45.

17. Siegenberg, D.; Baynes, R.; Bothwell, T. H.; MacFarlane, B. J.; Lamparelli, R. D.; Car, N. G.; MacPhail, P.; Schmidt, U.; Tal, A.; Mayet, F. Ascorbic acid prevents the dosedependent inhibitory effects of polyphenols and phytates on nonheme-iron absorption. Am. J. Clin. Nutr. 1991, 53 (2), 537-541.

18. Reddy, M. B.; Hurrell, R. F.; Cook, J. D. Estimation of nonheme-iron bioavailability from meal composition. Am. J. Clin. Nutr. 2000, 71 (4), 937-943.

19. Boccio, J.; Salgueiro, J.; Lysionek, A.; Zubillaga, M.; Weill, R.; Goldman, C.; Caro, R. Current knowledge of iron metabolism. Biol. Trace Elem. Res. 2003, 92 (3), 189-211.

20. Cook, J. D. Adaptation in iron metabolism. Am. J. Clin. Nutr. 1990, 51 (2), 301-308.

21. Hultén, L.; Gramatkovski, E.; Gleerup, A.; Hallberg, L. Iron absorption from the whole diet. Relation to meal composition, iron requirements and iron stores. Eur. J. Clin. Nutr. 1995, 49, 794-808.

22. Boccio, J. R.; lyengar, V. Iron deficiency: Causes, consequences, and strategies to overcome this nutritional problem. Biol. Trace Elem. Res. 2003, 94 (1), 1-31.

23. Boccio, J.; Monteiro, J. B. Fortificación de alimentos con hierro y zinc: pros y contras desde un punto de vista alimenticio y nutricional. Rev. Nutr., Campinas 2004, 17 (1), 71-78.

24. Brandis, K. The Physiology Viva: Questions and Answers; Australia Print and Copy: Southport, Australia, 2002; pp 198-201.

25. Ferrous Sulfate Tablets Mongraph. In The United States Pharmacopeia and National Formulary USP 32-NF 27; The United States Pharmacopeial Convention, Inc.: Rockville, MD, 2009; p 2603.

26. Ferrous FumarateTablets Monograph. The United States Pharmacopeia and National Formulary USP 32-NF 27; The United States Pharmacopeial Convention, Inc.: Rockville, MD, 2009; p 2598.

27. Waiver of In Vivo Bioavailability and Bioequivalence Studies for Immediate-Release Solid Oral Dosage Forms Based on a Biopharmaceutics Classification System; Guidance for Industry; U.S. Department of Health and Human Services, Food and Drug Administration, Center for Drug Evaluation and Research (CDER), U.S. Government Printing Office: Washington, DC, 2000.

28. Guideline of the Investigation of Bioequivalence; Committee for Medicinal Products for Human Use (CHMP), European Medicines Agency: London, 2010.

29. The United States Pharmacopeia and National Formulary USP 32-NF 27; The United States Pharmacopeial Convention, Inc.: Rockville, MD, 2009. 